\title{
Pair-Copula Analysis of Social Benefits Arising From Monopoly Expan- sion of State-owned Enterprises
}

\author{
Du Xue-Feng ${ }^{1 *}$ Ti'an Yi-Xiang $^{1}$ and Wang Kaiming ${ }^{2}$ \\ ${ }^{1}$ School of Management and Economics of UESTC, Chengdu, 611731, China; ${ }^{2}$ Tianfu College of Southwestern Univer- \\ sity of Finance and Economics, Mianyang, 621000, China
}

\begin{abstract}
With its growing popularity in the international arena of structure studies, the pair-copula method is used to analyze the social benefits arising from recent expansion of state-owned enterprises under the "expanding domestic demand" background. An empirical analysis was conducted with the financial data of top 100 state-owned listed companies during 2002-2013. The results show that, state-owned companies have been witnessing profound expansion since the release of the Ten Actions for Expanding Domestic Demand and Promoting Economic Growth promulgated by the State Council in November 2008. Monopoly expansion is not significantly correlated with financial performance but retains a significant positive correlation with social benefits. This indicates that monopoly expansion does not necessarily contribute to better financial performance but spurs state-owned enterprises to assume more social responsibilities.
\end{abstract}

Keywords: Monopoly expansion, pair copula, SE-DEA, social benefits of state-owned enterprises.

\section{INTRODUCTION}

Since the 21 st century, China has been overwhelmed by serious security incidents, such as Sanlu toxic milk powder, Guangxi Longjiang water pollution and PetroChina oil spill. In consequence, increasing attention is drawn to corporate social responsibility. Companies are urged by interested parties to fulfill their due responsibilities and make social contributions while pursuing economic growth. For this purpose, Shenzhen Stock Exchange issued the Notice on Social Guidelines for Listed Companies in September 25, 2006. According to this document, listed companies are encouraged to imitate international practices of social responsibility and disclose their reports thereof on a voluntary basis. On May 14, 2008, Shanghai Stock Exchange issued the SSE Guide to Environmental Information Disclosure of Listed Companies, which advocates prompt disclosure of corporate social responsibilities. This concerted effort ushered in a new era of corporate social responsibility movement in China. Currently, state-owned enterprises are still the mainstay of China's economy and the fulfillment of their social responsibilities is subject to growing attention. The global financial crisis in 2008 severely frustrated the economy and the Chinese government responded with a series of pump priming actions, such as the Ten Industries Revitalization Plan. These actions revitalized the economy, but also brought about some negative effects. Inflow of large amounts of bailout fund into large state-owned enterprises led to varying degrees of expansion in iron and steel, aviation, real estate and coal industries. Economists represented by $\mathrm{Wu}$ Jinglian expressed concern about this phenomenon and yearned for immediate attention from the government.
In the context of expanding domestic demand, can expansion of state-owned enterprises create better social benefits? In what way are social responsibilities and financial performance related? Research on these issues can help the authorities formulate industrial development plans for more efficient configuration of state resources to minimize the loss of state assets. This paper analyzed how the expansion of state-owned enterprises affects corporate social responsibility and financial performance and how the latter two are related. An empirical study was conducted using the financial data of top 100 state-owned listed companies. The results provide a yardstick for policy makers and managers of stateowned enterprises regarding the fulfillment of corporate social responsibilities.

\section{LITERATURE REVIEW}

A wide array of studies on corporate social responsibility have been conducted at home and abroad with scholars engaged in exploring the relationship between corporate social responsibility and financial performance. The conclusions, however, vary in three aspects: a negative correlation, a positive correlation, and an insignificant correlation.

Some scholars believe in a negative correlation between corporate social responsibility and financial performance. Vance (1975) [1] insists that investment and fulfillment of social responsibility are not an ideal solution. Ingam (1978) [2] holds that fulfilling social responsibility means higher costs which will lead to significant deterioration in financial performance. Li Zheng (2006) [3] concludes that corporate social responsibility and value presentation are negatively correlated, after analyzing the data of 521 enterprises listed in Shanghai Stock Exchange in 2003.

Nevertheless, many other researchers believe in a positive correlation between corporate social responsibility and 
financial performance. Moskowitz (1972) [4] concludes that active fulfillment of corporate social responsibility comes along with better financial performance, after analyzing the data of 14 outstanding enterprises. Cochran and Wood (1984) [5] together with Preston and O'Bannon (1997) [6] also believe in such positive correlation. For Porter and Vander Linde (1995) [7] together with Waddock and Graves (1997) [8], this positive correlation is even more significant according to the regression analysis results. Scholtens (2008) [9] further verified the significance of this positive correlation by using the OLS method based on the data of 289 companies. Lopez-Gamero and Molina-Azorin (2010) [10] hold that fulfilling social responsibility helps enterprises improve their competitiveness and positively affects financial performance. Lin, Yang and Liu (2009) [11] conducted an empirical study based on the data of 1,000 enterprises in Taiwan. Their conclusion is that fulfilling social responsibility has much more significant positive effect on financial performance in the long run than its short-term effect. An empirical study on some listed companies in China conducted by Shen Hongtao (2005) [12], Wen Subin and Fang Yuan (2008) [13] indicates a significant correlation between corporate social responsibility and financial performance. Zhang Chuan, Lou Zhukun and Gao Xinzi (2012) [14] conducted a study on the intrinsic relationship between corporate social responsibility and financial performance by using the simultaneous model based on the data of 76 state-owned enterprises. The result indicates that fulfilling social responsibility improves financial performance. According to the results of exploratory factor analysis and hierarchical regression analysis by Huo Bin and Zhou Yanhua (2014) [15] based on the data of 194 companies, there is a positive correlation between corporate social responsibility and financial performance and corporate reputation plays an intermediary role.

Some other scholars refuse any significant correlation between corporate social responsibility and financial performance, for example, Mc Willianms and Siegel (2000) [16] together with Maria, Fernando and Carles (2009) [17]. Fan Qi (2013) [18] conducted an analysis based on the data of state-owned listed enterprises and concluded with no significant correlation.

To sum up, most studies indicate a significant positive correlation between corporate social responsibility and financial performance, while others find a negative or even no correlation. Different methodology and measures are the fundamental reason for such deviation. Another factor is that less attention is paid to the impact of the expandingdomestic-demand policy since 2008 on social responsibility and financial performance of state-owned enterprises. By using the pair-copula method, this paper aims to analyze the impact of expansion of state-owned enterprises on their social benefits and the relationship between corporate social responsibility and financial performance. The purpose is to provide guidance for policy makers and managers of stateowned enterprises regarding active fulfillment of corproate social responsibilities.

\section{MODEL METHOD}

Most researches on the relationship between corproate social resposibility and financial performance employ the linear correlation coefficient method which, in the opinion of Embrechts (2003) [19], is inadequate to represent non-linear correlation between variables and may easily lead to great deviation. The copula function model is deemed to have the greatest potential in studying non-linear correlation between variables. The copula function links up joint distribution functions of multiple random variables with its marginal distribution and helps describe joint distribution of multiple random variables. It has been used by many scholaors to represent non-linear correlation between variables In despite of its maturity in characterizing bivariate correlation, the traditional copula theory is awkward in respect of multivariate correlation. To effectively overcome this drawback, the pair-copula method [20-22] was introduced to estimate the correlation of multiple variables based on bivariate copula. This method decomposes a multivariate joint density function into the product of a series of pair-copula modules and marginal density functions, thereby capturing a non-linear correlation between multiple assets and effectively helping the traditional copula function in describing correlation between multiple assets.

For high-dimensional distribution, there are a variety of logical structures for pair-copula decomposition, of which DVine and C-Vine are commonly used. Formula (1) and (2) show the joint density functions of C-Vine and D-Vine, respectively:

(1) C-Vine

$f\left(x_{1}, x_{2}, \ldots x_{n}\right)=\prod_{k=1}^{n} f_{k}\left(x_{k}\right) \cdot \prod_{j=1}^{n-1} \prod_{i=1}^{n-j} c_{j, j+i \mid 1, \ldots, j-1}$

(2) D-Vine

$f\left(x_{1}, x_{2}, \ldots x_{n}\right)=\prod_{k=1}^{n} f_{k}\left(x_{k}\right) \cdot \prod_{j=1}^{n-1} \prod_{i=1}^{n-j} c_{i, i+j \mid i+1, \ldots, i+j-1}$

where:

$f\left(x_{1}, x_{2}, \ldots x_{n}\right)$ is the joint density function and $f_{k}\left(x_{k}\right)$

is the marginal density function. $c_{i, i+j \mid i+1, \ldots, i+j-1}$ and

$c_{j, j+i \mid 1, \ldots, j-1}$ used to characterize the correlation structure are defined as follows:

$$
\begin{aligned}
& c_{i, i+j \mid i+1, \ldots, i+j-1}=c_{i, i+j \mid i+1, \ldots, i+j-1}\left(F\left(x_{i} \mid x_{i+1}, \ldots, x_{i+j-1}\right),\right. \\
& \left.F\left(x_{i+j} \mid x_{i+1}, \ldots, x_{i+j-1}\right)\right) \\
& c_{j, j+i \mid 1, \ldots, j-1}=c_{j, j+i \mid 1, \ldots, j-1}\left(F\left(x_{j} \mid x_{1}, \ldots, x_{j-1}\right), .\right. \\
& \left.F\left(x_{j+i} \mid x_{1}, \ldots, x_{j-1}\right)\right)
\end{aligned}
$$

The pair-copula density function contains a pair of conditional distribution functions $F(x \mid v)$ :

$$
c_{i, j \mid v}=c_{i, j \mid v}\left(F\left(x_{i} \mid v\right), F\left(x_{j} \mid v\right)\right)
$$

where:

$v$ is the condition in the conditional distribution function and is specific form depends on the vine structure. Each 


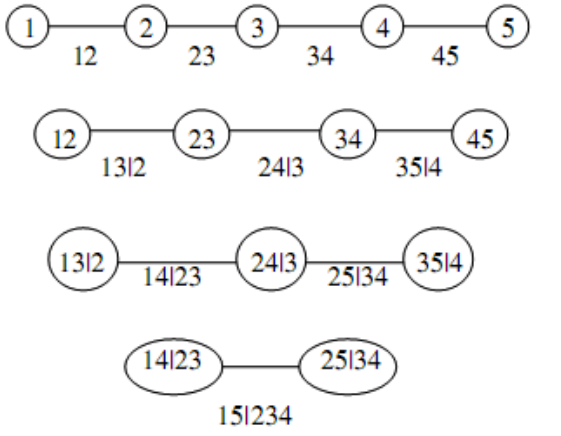

(a) D-vine

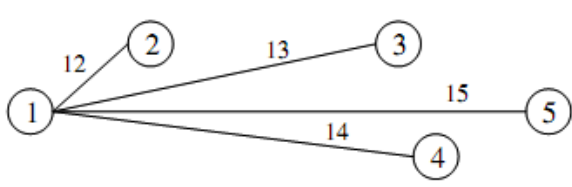

$\mathrm{T}_{1}$

$\mathrm{T}_{2}$

$\mathrm{T}_{3}$

$\mathrm{T}_{4}$
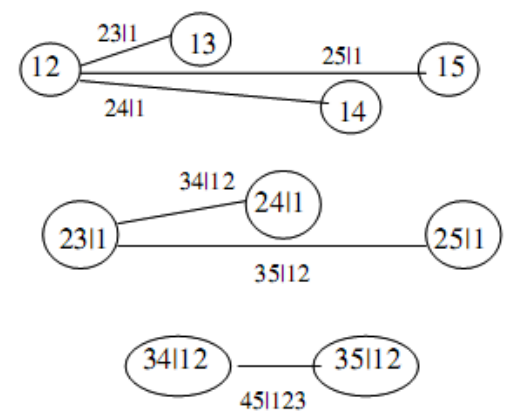

(b) C-vine.
$\mathrm{T}_{1}$

$\mathrm{T}_{2}$

$\mathrm{T}_{3}$

$\mathrm{T}_{4}$

Fig. (1).

$c_{i, j \mid v}$ decides the correlation coefficient $\rho_{i, j \mid v}$ of two random variables.

D-vine in Fig. (1a) and C-vine in Fig. (1b) represents five dimensions. The correlation structure of n-dimensional random variables can be represented with a n-dimensional vine composing $n-1$ trees, of which $k$ tree has $n-k+1$ nodes and the correlation between two nodes is described with a pair copula. The pair-copula function can be a common bivariate function, such as Gauss-copula, T-copula, Claytoncopula, Gumbel-copula, etc. D-vine applies when variables in data are independent of each other, while C-vine applies when there are key variables in data to guide other variables. A vine clearly shows the correlation between multiple random variables. In this paper, the pair-copula method is used to outline the non-linear relationship between monopoly expansion, corporate social responsibility and financial performance.

\section{DEFINITION OF VARIABLES AND DATA SOURCE}

\subsection{Definition of Variables}

\subsubsection{Corporate Social Responsibility}

Currently, the concept of corporate social resposniblity is still new to people. The concentric zone model and four hierarchical model are commonly used. In the concentric zone model, corporate social responsibility is circled in three concentric zones from the inside out: responsiblity for effectively executing economic functions, responsibility for executing economic functions as the social value changes, and responsibility for actively improving the social environmen. In the four hierachical model, corporate social responsibility is divided into four levels: economic responsibility, legal responsibility, ethical responsibility and charitable responsibility. Regardless of their wide application, these two models cannot provide a complete characterization of corporate social responsibility. In this paper, the measure invented by Shen Hongtao (2011) [23] is employed based on the contribution per share released by SSE in May 2008, which is represented by: Contribution per Share $=($ Net Profit + Income Tax Expense + Business Tax and Surcharges + Cash Pay-

ments to Employees + Employee Pay Payable of the Current Period - Employee Pay Payable of the Previous Period + Donation - Sewage Charge and Cleaning Fees)/Average of Initial and Final Number of Shares.

\subsubsection{Financial Performance}

The objectivity of financial performance will have a major impact on the results of an empirical study. Generally, traditional market indicators based on accounting data or financial indexes and stock yield cannot reflect the actual performance of enterprises in China. Taking account of the capital market imperfections, this paper employs the SEDEA method to calculate the enterprise efficiency to measure financial performance. DEA (Data Envelopment Analysis) is mainly used to analyze the relative efficiency of several decision-making units with the same type of input and output. Andersen, Petersen et al proposed the super-efficient DEA (SE-DEA) model by optimizing the traditional DEA model. The following formula shows the dual principle of SE-DEA:

$$
\text { s.t. }\left\{\begin{array}{l}
\min \theta \\
\sum_{j=1, j \neq k}^{n} \lambda_{j} X_{j}+S^{-}=\theta X_{k} \\
\sum_{j=1, j \neq k}^{n} \lambda_{j} Y_{j}-S^{+}=Y_{k} \\
\lambda_{j} \geq 0, j=1,2, \ldots, n \\
S^{-} \geq 0, S^{+} \geq 0
\end{array}\right.
$$

where:

$X_{j}, Y_{j}$ are the input and output matrixes of the decisionmaking unit $j$, respectively.

$\lambda_{j}$ is the planned decision variable.

$S^{-}$and $S^{+}$are the input and output relaxation matrixes, respectively. 
Table 1. Basic Statistics of Monopoly Expansion, Social Responsibility and Financial Performance of State-owned Enterprises.

\begin{tabular}{|c|c|c|c|c|c|c|}
\hline & \multicolumn{3}{|c|}{ Before Event Day } & \multicolumn{3}{c|}{ After Event Day } \\
\cline { 2 - 7 } & $\begin{array}{c}\text { Monopoly } \\
\text { Expansion }\end{array}$ & $\begin{array}{c}\text { Social } \\
\text { Responsibility }\end{array}$ & $\begin{array}{c}\text { Financial } \\
\text { Performance }\end{array}$ & $\begin{array}{c}\text { Monopoly } \\
\text { Expansion }\end{array}$ & $\begin{array}{c}\text { Social } \\
\text { Responsibility }\end{array}$ & $\begin{array}{c}\text { Financial } \\
\text { Performance }\end{array}$ \\
\hline \hline Mean & 0.033485 & 1.548053 & 0.688757 & 0.050120 & 3.049835 & 0.720770 \\
\hline Median & 0.034542 & 1.455224 & 0.651800 & 0.050936 & 2.567470 & 0.707850 \\
\hline Maximum & 0.038189 & 2.422003 & 0.826600 & 0.063057 & 5.358074 & 0.830150 \\
\hline Minimum & 0.025574 & 0.699321 & 0.580500 & 0.039037 & 1.258392 & 0.663675 \\
\hline Std & 0.004591 & 0.663070 & 0.094255 & 0.009487 & 1.556312 & 0.066623 \\
\hline Jarque-Bera & 0.455729 & 0.706677 & 0.803504 & 0.339469 & 0.361024 & 0.808798 \\
\hline Probability & 0.796232 & 0.702339 & 0.669147 & 0.843889 & 0.834843 & 0.667378 \\
\hline
\end{tabular}

$\theta$ is the performance of different units, which is a vector consisted of distances of different units to the effective frontier. A greater $\theta$ value indicates higher the performance. When $\mathrm{y}$, unit $j$ fails to achieve the optimal performance. When $\mathrm{y}$, unit $j$ reaches the optimal performance. When $\mathrm{y}$, unit $j$ exceeds the optimal performance.

Estimating the performance of state-owned enterprises through SE-DEA method requires setting of the input and output indicators. According to the microeconomic production theory, main inputs of a company include capital and labor, while main outputs include output value and yield. Given the desirability of this idea and indicators, this paper selects asset-liability ratio, total assets and employee pay payable as the inputs and total revenue, gross profit and net profit as outputs.

\subsection{Data Source}

Data referred to in this paper was obtained from the GTA CSMAR series database. Top 100 state-owned enterprises listed in 2011 were selected as the object of study. The financial data used dates from December 312002 to June 30 2013. Enterprises in the financial and insurance sector were excluded due to its special nature. For time consistency, enterprises with missing data were excluded. Social responsibility of state-owned enterprises was measured by contribution per share, financial performance was calculated using the SE-DEA method, and monopoly degree was measured by aggregate market value of the company/aggregate market value of the sector.

\section{EMPIRICAL ANALYSIS}

In order to mitigate the impact of the global financial crisis in 2008, the Chinese government initiated a series of pump priming actions, such as the Ten Industries Revitalization Plan, at the beginning of 2009. The following context analyzes how the expansion of state-owned enterprises changes before and after December 31, 2008 (event day). The purpose is to verify the existence of expansion of stateowned enterprises and provide a basis for future study.
Table 1 shows the descriptive statistics of and changes in monopoly expansion, social responsibility and financial performance of state-owned enterprises before and after the event day.

In the table, the mean and median level of monopoly expansion increases from 0.033485 to 0.050120 and from 0.034542 to 0.050936 before and after the event day, respectively. Dramatic monopoly expansion of state-owned enterprises since 2009 indicates that the financial crisis severely frustrated the capital chain of private enterprises. Inflow of large amounts of bailout funds into state-owned enterprises and macro-control provided them a chance of large-scale acquisition. This led to an awkward situation in which stateowned enterprises advance but private enterprises retreat. The median level of social responsibility increases by nearly $100 \%$ from 1.548053 before the event day to 3.049835 after the event day. This signifies greater investment of stateowned enterprises in social responsibility after 2009. The financial performance indicator shows a slight increase, indicating no dramatic change before and after the event day. To trace the fundamental reason, the global financial crisis severely impacted state-owned enterprises and huge bailout funds cannot obliterate the negative impacts.

The following context analyzes dynamic changes in monopoly expansion, social responsibility and financial performance of state-owned enterprises before and after 2009 .

Fig. (2). shows a curve of monopoly expansion of stateowned enterprises from 2002 to 2013.

In the figure, the medial level of monopoly expansion of state-owned enterprises increases slightly from 2002 to 2009 but greatly since 2009. After 2011, the upward trend relaxes but is still higher than the level before 2009. This indicates that after 2009, inflow of bailout funds into state-owned enterprises made the capital situation of private enterprises ever more critical. For sustained business instead of bankruptcy, private enterprises desperately sought for relief and stateowned enterprises took this opportunity to initiate large-scale acquisition, resulting in expansion. The national economy has gradually returned to a healthy state starting from 2011, which improves the business environment of the private sector and drives down monopoly expansion of state-owned enterprises. 


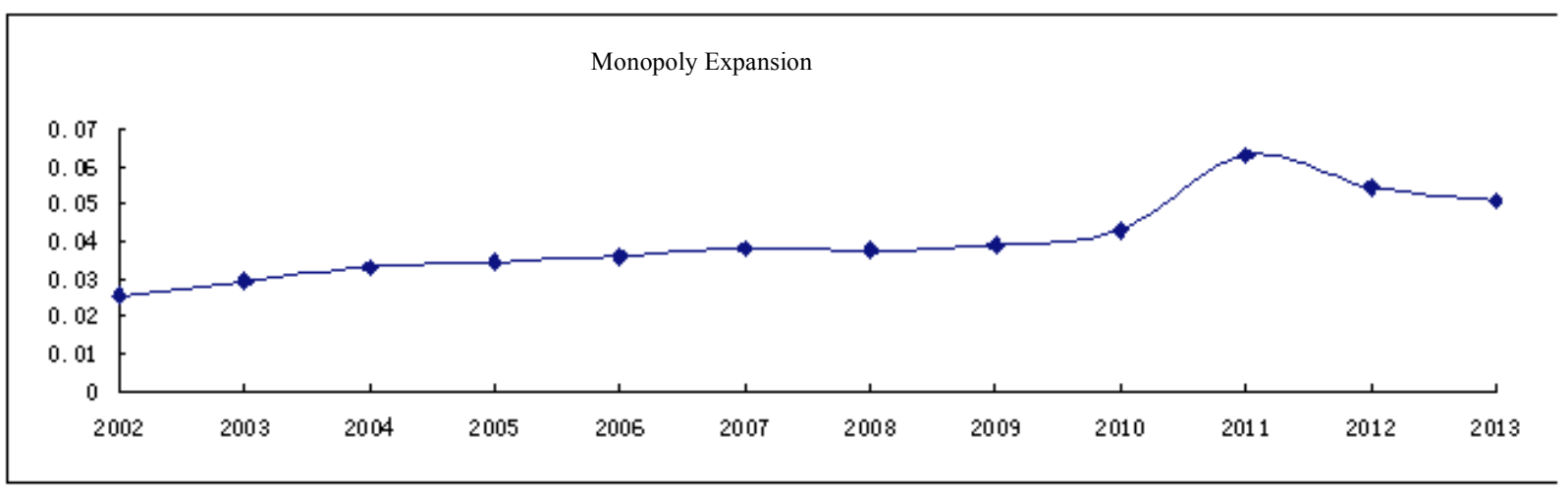

Fig. (2). Monopoly Expansion Curve of State-owned Enterprises from 2002 to 2013.
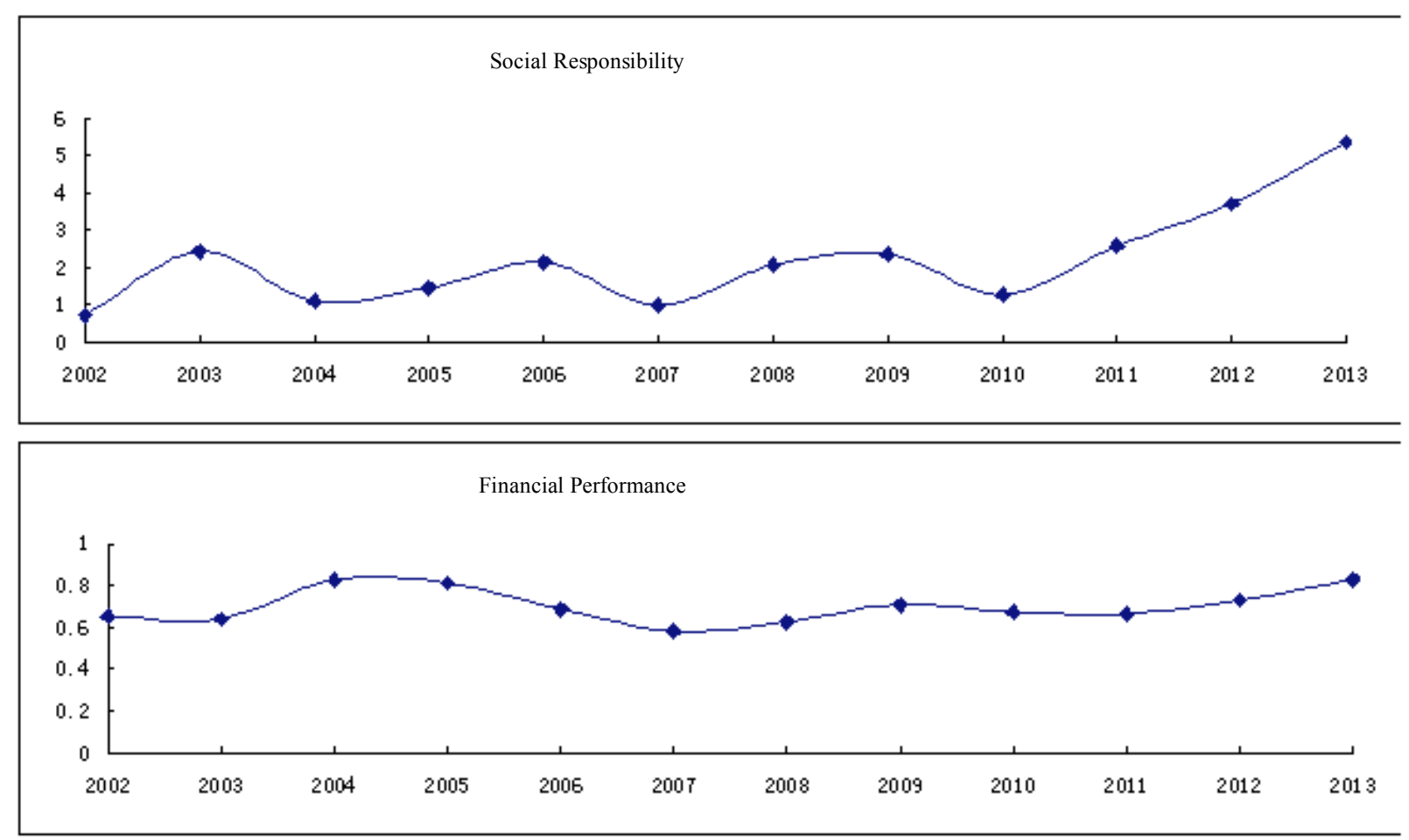

Fig. (3). Social Responsibility and Financial Performance Curves of State-owned Enterprises from 2002 to 2013.

Fig. (3) shows a curve of social responsibility and financial performance of state-owned enterprises from 2002 to 2013.

In the figure, the level of social responsibility of stateowned enterprises declines slightly and then gradually increases before and after 2009. The level of financial performance, however, shows no significant change but stays at about $70 \%$. This indicates that, since the release of the SSE Guide to Environmental Information Disclosure of Listed Companies in 2008, state-owned enterprises began to pay more attention to their social responsibilities and increase investment in this area. On the other hand, the financial crisis in 2008 destructed the domestic and international market environment and pump priming actions failed to boost the overall performance of state-owned enterprises, leaving large room for improving the efficiency. For stronger competiveness, policy makers and managers of state-owned enterprises are expected to further optimize the governance structure and improve the operational efficiency.
The foregoing analysis further confirms the very existence of expansion of state-owned enterprises after 2008. For in-depth analysis of the impact of monopoly expansion on state-owned enterprises themselves, the following context analyzes the complex relationship between monopoly expansion, social responsibility and financial performance using the pair-copula technique. Correlation analysis is conducted by the following steps:

1) Estimate the Pearson linear correlation coefficient and the Kendall rank correlation coefficient between monopoly expansion, social responsibility and financial performance of state-owned enterprises.

2) Use the coefficients obtained in step 1 as initial values and employ the Maximum Likelihood method to estimate the correlation (estimated with the pair-copula technique) when bivariate copula functions are different.

3) Judge which model can best estimate the correlation based on the likelihood function, so as to analyze the correla- 
Table 2. Estimated correlation coefficients.

\begin{tabular}{|c|c|c|c|c|}
\hline & \multicolumn{2}{|c|}{ Pearson Linear Correlation Coefficient } & \multicolumn{2}{c|}{ Kendall Rank Correlation Coefficient } \\
\hline \hline & SHZR & SE-DEA & SHZR & SE-DEA \\
\hline LDKZ & 0.6182 & 0.0951 & 0.8255 & 0.1488 \\
\hline SHZR & -- & 0.4154 & -- & 0.6072 \\
\hline
\end{tabular}

Note: LDKZ indicates monopoly expansion, SHZR indicates social responsibility, and SE-DEA indicates financial performance.

Table 3. Pair copula-based estimations of related parameters.

\begin{tabular}{|c|c|c|c|c|}
\hline $\begin{array}{c}\text { Type of Pair Copula } \\
\text { Between Vane Nodes }\end{array}$ & $\rho_{12}$ & $\rho_{13}$ & $\rho_{23 \mid 1}$ & Likelihood Function \\
\hline \hline T-copula & $0.6571(0.4084)$ & $0.2148(0.3202)$ & $0.5187(0.3168)$ & $8.8836(0.9895)$ \\
\hline Clayton-copula & $1.8678(0.3096)$ & $10.9976(3.1988)$ & $1.4634(0.7405)$ & -9.4120 \\
\hline Gumbel-copula & $1.9144(0.4374)$ & $0.8557(0.6840)$ & $1.6933(0.3283)$ & -7.1144 \\
\hline Gauss-copula & $2.0691(0.4770)$ & $1.6134(0.4523)$ & $0.5487(0.1913)$ & -6.5855 \\
\hline
\end{tabular}

Note: Figures in parentheses are estimated standard deviations.

tion between monopoly expansion, social responsibility and financial performance of state-owned enterprises.

Table 2 lists the estimated Pearson linear correlation coefficient and Kendall rank correlation coefficient between monopoly expansion, social responsibility and financial performance of state-owned enterprises.

In the table, the linear correlation coefficient between monopoly expansion and social responsibility is 0.6182 , indicating a positive correlation which is further verified by the Kendall rank correlation coefficient. Both the Pearson linear correlation coefficient and the Kendall rank correlation coefficient show a weak correlation between monopoly expansion and financial performance, indicating that the former does not necessarily improves the latter. These two coefficients also prove a positive correlation between social responsibility and financial performance. To conclude, monopoly expansion enhances social responsibility but fails to do the same to financial performance and better fulfillment of social responsibility brings about higher financial performance. Nevertheless, this conclusion cannot represent the relationship between the other two indicators when one indicator is fixed, for example, social responsibility and financial performance under monopoly expansion. For this reason, the pair-copula technique is employed to estimate the correlation between multiple elements.

Regardless of their advantage in analyzing bivariate correlation, the Pearson linear correlation coefficient and the Kendall rank correlation coefficient are unable to measure multi-variate impact upon one another, leading to deviation between the estimated and actual correlation between multiple variables. Because of the similarity between D-vine and $\mathrm{C}$-vine in the pair-copula technique regarding the three indicators, only correlations under $\mathrm{C}$-vine are considered in this paper. As the pair-copula technique estimates non-linear correlations, values obtained from the Kendall rank correlation coefficient are used as input parameters of the pair- copula function. Gauss-copula, T-copula, Clayton-copula and Gumbel-copula are used as alternate bivariate copulas between pair-copula vane nodes. The Maximum Likelihood method is employed to obtain the likelihood function which is used to judge which model best analyzes the correlation between social responsibility and financial performance.

Table 3 shows the correlations between monopoly expansion, social responsibility and financial performance of stateowned enterprises using the pair-copula technique and lists the estimated values of related parameters.

In the table, the likelihood functions of the correlation model at T-copula, Clayton-copula, Gumbel-copula and Gauss-copula vane node are $-9.4120,-7.1144,-6.5855$ and 6.0798 , respectively. This indicates that the T-copula vane node provides the most reasonable correlation. Therefore, Tcopula is adopted to analyze the correlations between monopoly expansion, social responsibility and financial performance. The correlation coefficient between monopoly expansion and social responsibility is 0.6571 , indicating a strong positive correlation. However, the correlation coefficient between monopoly expansion and financial performance is 0.2148 and there is no proof that the former enhances the latter, indicating a weak correlation. The correlation coefficient between social responsibility and financial performance under monopoly expansion is 0.5187 and great differs from the unconditional correlation coefficient. To conclude, the unconditional correlation coefficient can only characterize bivariate correlations and is inadequate for conditional multi-variate correlations. The pair-copula technique, however, clearly locates the intrinsic regional correlations in sequence and better analyzes the impact of social responsibility on financial performance under monopoly expansion.

\section{CONCLUSION}

In the context of expanding domestic demand, this paper analyzes the relationship between monopoly expansion, so- 
cial responsibility and financial performance of state-owned enterpsires and verifies the correlation between the latter two indicators under monopoly expansion by using the paircopula technique. An empirical study is conducted based on the financial data of top 100 state-owned enterprsies listed during 2002-2013. The following conclusions are drawn.

First, the empirical study shows that, since the grant of bailout funds up to RMB 4,000 billion Yuan in 2009 by the Chinese government, state-owned enterprises experienced a significantly higher level of monopoly and their scale further expanded. This finding verifies the rationality of perspectives of many economists, such as $\mathrm{Wu}$ Jinglian and Wang Xiaolu. The government is expected to attach great importance on the impact of expasnion of state-owned enterprises on the national economy while lauching macro-control policies.

Secondly, the analysis result reveals no signficaint corealtion between monopoly expansion and financial performance but a significant positive correlation between monopoly expansion and social resposniblity. This indicates that finaical performance of state-owned enterprsies has not changed greatly, but greater investment has been made in social responsiblity. Both social resposniblity and financial performance need to be considered when estimating the impact of monopoly expansion on state-owned enterprises themselves. Policy makers and managers of state-owned enterprises are expected to encourage state-owned enterprises to better fulfill social responsibilities, improve innovation capabilities, and develop new business patterns so that they provide more benefits for the national economy.

\section{CONFLICT OF INTEREST}

The authors confirm that this article content has no conflict of interest.

\section{ACKNOWLEDGEMENTS}

This work is supported by the fund program of the Humanities and Social Sciences Project of the Ministry of Education of China: "Exploration of Reasons and Inherent Mechanism of Impact of Sovereign Credit Rating Downgrade on Global Economy and Countermeasures" (12YJA790125)

\section{REFERENCES}

[1] S. Vance, "Are Socially Responsible Firms Good Investment Risks?" Management Review, vol.64, pp.18-24, 1975.

[2] R. W. Ingram, "An Investigation of the Information Content of Certain Social Responsibility Disclosures" Journal of Accounting Research, vol.16, pp. 270-285, 1978.

[3] Z. Li, "A Study on Correlation Between Corporate Social Responsibility and Enterprise Value" China Industrial Economics, vol. 2, pp. 77-83, 2006.
[4] M. Milton, "Choosing Socially Responsible Stocks" Business and Society Review, vol.1, pp. 71-75, 1972.

[5] P. Cochran, and R. Wood, "Corporate Social Responsibility and Financial Performance" Academy of Management Journal, vol.27, pp. 42-56, 1984.

[6] L. E. Preston, and D. P. O'Bannon, “The Corporate Social Financial Performance Relationship" Business and Society, vol. 36, pp. 419-429, 1997.

[7] M. E. Porter, "Vander Linde C. Green and Competitive: Ending the Stalemate" Harvard Business Review, vol.73, no. 5, pp. 120-134, 1995 .

[8] S. Waddock, and S. Graves, "The Corporate Social Performance Financial Performance Link" Strategic Management Journal, vol. 18 , no.4, pp. 303-319, 1997.

[9] B. Scholtens, "A Note on the Interaction Between Corporate Social Responsibility and Financial Performance" Ecological Economics, vol.68, no. 1 , pp. 46-55, 2008.

[10] M. D. López-Gamero, J. F. Molina-Azorín, and E. Claver-Cortés, "The Potential of Environmental Regulation to Change Managerial Perception, Environmental Management, Competitiveness and $\mathrm{Fi}$ nancial Performance" Journal of Cleaner Production, no. 18, pp. 963-974, 2010.

[11] C. Lin, H. Yang, and D. Liu, "The Impact of Corporate Social Responsibility on Financial Performance: Evidence from Business in Taiwan" Technology in Society, no.31, pp. 56-63, 2009.

[12] H. Shen, "A Review on Relationship Between Corporate Social Responsibility and Financial Performance" Doctoral Dissertation of Xiamen University, pp. 45-50, 2005.

[13] S. Wen, and Y. Fang, "An Empirical Study on Corporate Social Responsibility and Financial Performance" China Industrial Economics, no.10, pp. 110-160, 2008.

[14] C. Zhang, Z. Lou, and X. Gao, "An Empirical Study on Social Responsibility and Financial Performance of State-owned Enterprises" Review of Corporate Governance, vol. 11, pp. 89-95, 2012.

[15] B. Huo, and Y. Zhou, "A Study on Correlations Between Corporate Social Responsibility, Corporate Reputation and Financial Performance" Industry, Technology and Economy, no.1, pp. 59-65, 2014.

[16] A. Mc William, and D. Siegel, "Corporate Social Responsibility and Financial Performance: Correlation or Misspecication?" Strategic Management Journal, vol. 21, no.5, pp. 603-609, 2000.

[17] M. D. Gil-Estallo, F. Gin-de-la-Fuente, and C. G. Miquela, "Benchmarking Corporate Social Responsibility within Spanish Companies" International Advances in Economic Research, vol. 5, no.2, pp. 207-225, 2009.

18] Q. Fan, "A Study on Correlation Between Corporate Social Responsibility and Financial Performance of State-owned Listed Companies" Financial and Accounting Monthly, vol. 6, pp. 25-28, 2013.

[19] P. Embrechts, "Dependence Structures for Multivariate High Frequency Data in Finance" Quantitative Finance, vol. 3, pp. 1-14, 2003.

[20] C. Czado, "Pair-copula Constructions of Multivariate Copulas, In: Jaworski P, Durante F, Hardle W, Rychlik T (Eds.), Copula Theory and Its Applications" Berlin: Springer, 2010.

[21] D. Kim, J. Kim, S. Liao, and Y. Jung, "Mixture of D-vine Copulas for Modeling Dependence" Computational Statistics \& Data Analysis, vol. 64, pp. 1-19, 2013.

[22] S. Sriboonchitta, J. Liu, V. Kreinovich,, and H. T. Nguyen, "A Vine Copula Approach for Analyzing Financial Risk and Comovement of the Indonesian" Philippine and Thailand Stock Markets, Advances in Intelligent Systems and Computing, vol. 251, pp. 245-257, 2014.

[23] H. Shen, L. Wang, and T. Wan, "Are Social Responsibility Reporting and Disclosure Effective? An Analysis Based on Corporate Reputation Theories" Auditing Research, no.4, pp. 87-93, 2011. 